\title{
Positive reinforcement: An extension of the Premack principle to response chains
}

ROBERT W. SCHAEFFER

FLORIDA STATE UNIVERSITY

Premack's principle, which applies only to response pairs, was tested on response chains composed of three differentially probable responses, arranged in two different sequences. The principle applied to one chain, but not to the other. A revision of Premack's principle is proposed which permits an account of the reinforcement relations that may be obtained between the responses which compose a response chain, as well as an account of the reinforcement relation between response pairs.

Premack's (1965) reinforcement principle may, as stated, be applied only to pairs of responses (i.e., for any pair of responses that are concurrently and freely available to an organism, the most probable response will, when subsequently made contingent upon the less probable response, reinforce the less probable response; but, if the less probable response is made contingent upon the more probable response, reinforcement of the more probable response will not occur). Much behavior, however, involves complex behavioral chains and multiple contingencies in which the $S$ must perform one response to gain access to a second; performance on the second response then gives access to a third, etc.

Can Premack's principle by applied without revision to response chains that involve multiple contingencies? Consider a case in which three, rather than two, differentially probable responses are avallable to a $\mathrm{S}$. For this three-response case, two of the many possible contingencies that may be scheduled are of particular relevance to the present study: First, with the most probable response (C) as the last member of the chain, and an intermediate probability response (B) contingent upon the least probable response (A), responses $A, B$, and $C$ would be ordered in terms of increasing probability; for this case, the principle predicts that responses $A$ and $B$ should be reinforced, since the chain is ordered so that a more probable response is always contingent upon a less probable response. Second, with $\mathrm{C}$ as the last member of the chain, and response $A$ contingent upon response $B$, the response chain of $B, A$, and $C$ would not be ordered in terms of increasing probability. For this case, the principle predicts that reinforcement of response $B$ should not occur, since $B$ is more probable than A.

The purpose of the present study was to investigate both of the multiple response contingencies described above.

Method

A Sprague-Dawley female albino rat, about 370 days old, with a previous history (64 sessions) of responding on a drink-to-run contingency, served as the S. From time of receipt in the laboratory, $S$ had been ad lib maintained on food and water in its home cage; this regime was continued throughout the present experiment.

The apparatus, which has been described in detail elsewhere (Schaeffer, 1966), consisted of an activitywheel test chamber which provided for (1) controlled availability of the wheel for running, (2) pneumatic presentation and retraction of drinking tubes and levers, and (3) the arrangement of multiple contingencies between running, water drinking, and bar pressing. All programming was accomplished by standard electromechanical devices. Each bar press, lick, and 90 degree wheel revolution was recorded by counters and an Esterline-Angus split-head, digital-analog recorder.

The S was tested, successively, using 16 daily 3-hr. test sessions per condition, under the following experimental conditions: operant level sessions; a bar press to drink to run contingency; operant level sessions; a drink to bar press to run contingency; operant level sessions.

In the operant level sessions, all three responses were concurrently and freely available for the $S$ to choose among them. In the bar press to drink to run contingency sessions, the lever was present when the $S$ was placed in the test chamber, but the tube was retracted and the wheel was braked. In these sessions, presentation of the tube was contingent upon a single depression of the lever. Five licks on the tube were then required to release the brake and make the wheel avallable for running for a 10-sec. period. At the end of the 10-sec. period, the wheel was braked, the tube retracted, and $S$ was free to begin a new trial by a single bar press.

In the drink to bar press to run contingency, the tube was freely available when the $S$ was placed in the test chamber, but the lever was retracted and the wheel was braked. The initial presentation of the lever was contingent upon five licks on the tube. A single bar press was then required to release the wheel brake and make the wheel available for running for 10 sec. When the wheel-running period timed out, the wheel was braked, the lever was retracted, and S was free to initiate a new trial by licking the tube five times.

\section{Resulis and Discussion}

Figure 1 summarizes the data from the last six sessions of each experimental condition. Although the data are shown as mean number of responses emitted, each response is readily converted to the response 


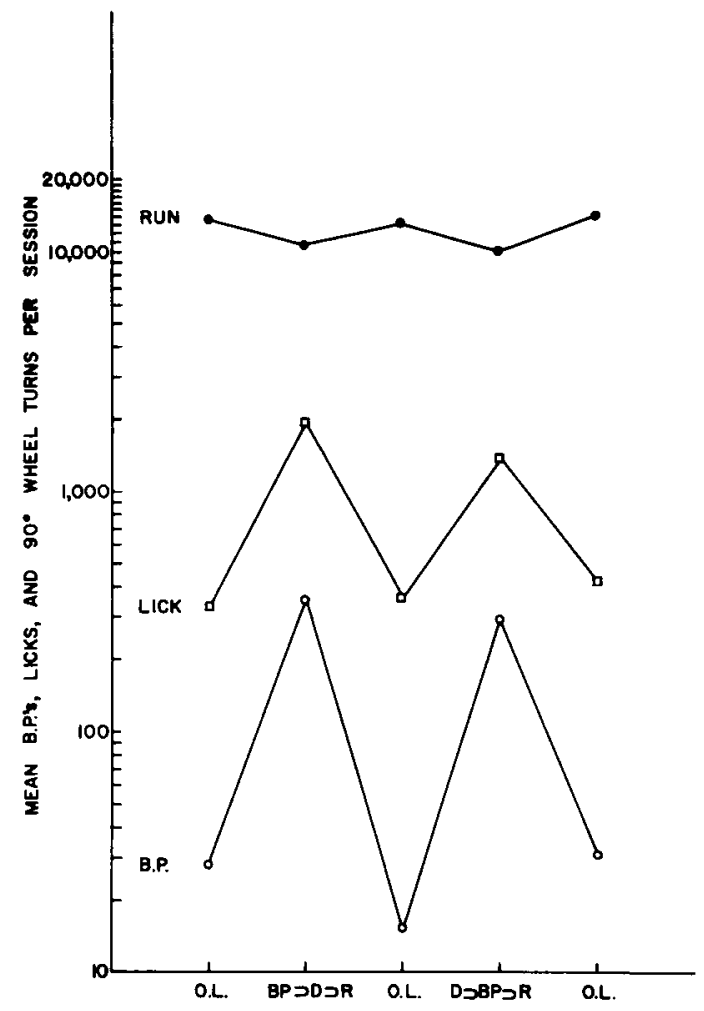

Fig. 1. Mean bar-presses, licks and 90 degree wheel tums in the last six sessions of each experimental condition.

duration measure required by Premack (1965). Both licking and running in the rat occur at a relatively constant rate (cf.; Premack, 1965). The modal licking and running rates for the $S$ in the present study were $6 \mathrm{licks} / \mathrm{sec}$. and 1.25 revolutions/sec. The modal bar press rate, based on response sampling, was 4 responses/sec. Thus, in the first operant level sessions, mean time spent bar pressing, drinking, and running was $7.3,56.3$, and 4646.1 sec., respectively. Comparable response duration values may be computed for each experimental condition, but it is obvious that the same ordinal response probabilities which were obtained in the first operant level sessions held for all subsequent conditions. As is also obvious from Fig. 1, both contingencies produced increments in bar pressing and drinking, relative to the operant level rates of these responses. Relative to its operant level, rate of running, the terminal response in both response chains, decreased slightly in both contingencies, which is consistent with the results of previous studies that use only response pairs (Premack, 1965).
The conceptual validity of Premack's suggestion that reinforcement involves a specific, reversible relation between responses, rather than a non-reversible relation between specific responses and specific stimuli, is readily apparent in many cases (e.g., running, drinking, and eating reinforce bar pressing, but bar pressing does not reinforce running, drinking, and eating). Further, the empirical validity of his principle has been shown, in a variety of situations, in predicting which of any two concurrently available responses may be used in subsequent contingencles as the reinforcing and/or reinforceable response (Premack, 1965). Although the present results indicate that his principle cannot, as stated, be applied unequivocably to response chains, with the following revision the principle might possibly encompass both response pairs and response chains: When several responses are concurrently and freely available to a $S$, for any pair of responses in the set, a more probable response will reinforce any less probable response; for any response chain within the set, the most probable response within that set or subset will reinforce all chained combinations of those less probable responses. Intuitively, some point will occur where the most probable response will, due to lack of proximity to earlier responses in the chain or the probability arrangement of the preceding responses, lose its reinforcing effectiveness (i.e., acquisition of a complex behavioral chain should be facilitated when responses are ordered in terms of increasing probability, and inhibited if the responses are ordered in any other fashion). Tests of the extent of facilitation or inhibition of chatning as a function of member of responses in the chain, response probabilities, disparities between response probabilities, and response sequencing are beyond the scope of the present study, but the present report does serve as a starting point from which tests of facilitation or inhibition of chaining as a function or response probability and disparities between response probabilities, as well as the adequacy of the present revision of Premack's principle may be initiated.

\section{References}

Premack, D. Reinforcement theory. In D. Levine (Ed.), Nebraska Symposium on motivation. Lincoln: University Nebraska Press, 1965.

Schaeffer, R. W. A new device for programming contingencies between drinking, running, and lever-pressing. J.exp. Anal. Behav., 1966, 9, 529-533.

\section{Note}

1. Supported by Public Health Service Research Grants MH08775 and MH12025 from the National Institute of Mental Health. 